\title{
"EL REMO, NUESTRO DEPORTE, REQUIERE AGUA LIMPIA". EXPERIENCIAS INNOVADORAS DE SANEAMIENTO DEL AGUA URBANA ENTRE CLUBES DE REMO DE FLORIANÓPOLIS Y AMSTERDAM
}

\author{
Cristhian Fernando Caje Rodriguez
}

\section{Introducción $^{2}$}

El aumento constante de resíduos sólidos urbanos ${ }^{3}$ en las aguas de Florianópolis y Amsterdam es algo que preocupa a atletas y simpatizantes del remo. El agua es un elemento omnipresente en el paisaje urbano de estas dos ciudades, convirtiéndolas en lugares ideales para la práctica del remo. Sin embargo, el aumento constante de residuos sólidos es un problema que se agrava cada día en el cotidiano citadino. El presente trabajo, se desenvolvió a partir del intercambio académico con la Frive Universiteit Amsterdam, posibilitado por el programa Capes/Nuffic, en carácter de doutorado sanduíche y trata entender las diferentes respuestas que se dan a este problema en estos contextos económicamente desiguales.

Entre Brasil y Holanda existe una gran disparidad en relación a la gestión de los servicios de agua potable y saneamiento urbano, como se esperaba. Si bien ambos presentan pequeñas diferencias en los estándares de potabilidad del agua y lineamientos para la descarga de efluentes, lo que podemos observar a simple vista, son grandes diferencias no sólo en relación a características geográficas y ambientales, como extensión territorial y disponibilidad de recursos, sino principalmente en relación a la gestión y la participación de las partes publico e privada, es decir, gobierno, proveedor de servicios y población en general.

\footnotetext{
${ }^{1}$ Universidade Federal de Santa Catarina, Brasil. Email: cristhiancaje@gmail.com ORCID id: https://orcid.org/0000-0002-8713-7872

2 nvestigación financiada por el Consejo Nacional de Desarrollo Científico y Tecnológico (CNPq) a través de la Beca de Extensión, sobre la supervisión de la Dra. Carmen Silvia Rial, y por la Coordinación de Perfeccionamiento de Personal de Nível Superior (CAPES) através da Bolsa de Pós-Doctorado en el Exterior por el Programa CAPES/NUFFIC na Vrije Universiteit Amsterdam (VU - Amsterdam), cordenados por la Dra. Carmen Silvia Rial y el Dr. Freek Colombijn. Este texto fue aceptado como comunicación oral para el II International APEB-NL Conference, Amsterdam - Holanda, en febrero de 2019. El evento fue organizado por la Asociación de investigadores y estudiantes de Pós Graduación brasileños y brasileñas en Holanda.

${ }^{3}$ Consideramos como residuos sólidos urbanos (RSU) a los restos generados por distintas actividades en los núcleos urbanos, incluyendo aquí tanto los de carácter doméstico como los provenientes de cualquier otra actividad.
} 
Establecer una comparación es de gran relevancia para pensar alternativas de políticas públicas para el reciclaje y la reutilización del agua, especialmente en Florianópolis. Y, por sobre todo, pensar esas alternativas dentro de una perspectiva de economía circular, donde residuos sólidos puedan ser re utilizados como insumos para la producción de nuevos productos - como ha sido la experiencia de los holandeses más alineados a los objetivos de Desarrollo Sostenible de la agenda 2030, implementada por las Naciones Unidas. Así como los clubes de remo pueden ayudar a pensar cómo proteger el medio ambiente, el clima y garantizar que las personas disfruten de agua limpia en sus actividades deportivas.

\section{"El remo, nuestro deporte, requiere agua limpia"}

Dentro una coyuntura global para hacer frente a esta problemática, surgió el movimiento FISA WWF Strategic Alliance ${ }^{4}$, en 2011 . Y se instala en varios lugares del mundo como parte de una cooperación internacional entre La Federación Internacional de Remo Mundial (FISA) y la World Wide Fund for Nature (WWF International), que, por medio del Fondo Mundial para el Agua, vienen utilizando el remo deportivo para educar y crear conciencia sobre la necesidad de mantener el agua libre de residuos sólidos.

La conexión entre agua limpia y remo nos parece obvia, y como enuncia el título del documento firmado por estas instituciones - y que inspira el título de este trabajo "el remo, nuestro deporte, requiere agua limpia". Con estas reflexiones propongo una discusión antropológica que nos aproxime más a un entendimiento vía comparación de experiencias innovadoras y soluciones locales entre Amsterdam y Florianópolis. Ya que, según Matos de Souza (2016:4), Brasil se enfoca en elevar sus tarifas de servicio sin preocuparse por la calidad y el impacto en el medio ambiente. Ya Holanda, con altos niveles de calidad y servicio (casi todos), se preocupa por buscar alianzas, nuevas tecnologías más sostenibles. y una participación más efectiva de la sociedad en temas relacionados con el saneamiento ambiental.

\footnotetext{
${ }^{4}$ Para más información sobre el proyecto, lea en el site oficial de la FISA, http://www.worldrowing.com/environment/fisa-wwf-strategic-alliance/ accesado en mayo de 2019.
} 
Es común que, cuando apuntamos para problemas de grandes metrópolis ${ }^{5}$, nos refiramos comúnmente a un "problema cultural, local", de procesos y resultado de una mala gestión municipal o incluso relacionada a los bajos niveles de desarrollo de recursos humanos. Esto reduce mucho su interpretación. Una mirada comparativa, y especialmente dirigida a las experiencias de los remeros y remeras y su manejo de lo que llamamos comúnmente de "basura", intercalando contextos, viendo con otros ojos, podemos notar de cómo los residuos ganan nuevo significado como material potencialmente activo. Los ejemplos que traigo aquí pueden ser considerados como casos de experiencias de innovación socio técnica (Latour, 2005), y que compartidas, tienen la capacidad de transformar el medio ambiente. Y con el objetivo de contribuir con el debate sobre la búsqueda por soluciones creativas y sostenibles ${ }^{6}$, que eviten agotar los recursos no renovables del agua.

Parto de la premisa apuntada por Stengers (2014), de que el problema de la contaminación es un desafío para todas las áreas del conocimiento y en especial para el área de las humanidades. La perspectiva comparativa, propia de la antropología, contribuye para imaginar futuros posibles a partir de estas dos realidades bien diferentes. Este trabajo, que surge como parte de mi tesis de doctorado - que tuvo como fondo la reforma urbanística de Florianópolis y las transformaciones sociales y culturales ocurridas a partir de la llegada del remo deportivo a inicios del siglo XX (Caje, 2020: 57) - va al encuentro de la experiencia de ocho meses como investigador visitante, junto al proyecto "Economía circular: antropologías de la basura/ de los residuos sólidos y experiencias innovadoras entre Holanda y Brasil ${ }^{7}$ (Rial, 2016) del

\footnotetext{
${ }^{5}$ Florianópolis fue considerada como una metrópoli brasileña solo en 2018, según los parámetros del Instituto Brasileño de Geografía y Estadística (IBGE) según la encuesta Regiones de Influencia de Ciudades 2018 (REGIC 2018).

6 Los términos "desarrollo sostenible", “desarrollo sustentable", "sostenibilidad" y "sustentabilidad" han generado un debate sobre sus usos dentro la lengua española. Tratando de establecer diferencias entre el origen anglo saxon del concepto, que se han venido utilizando como sinónimos, sobre todo cuando estas palabras se mencionan en contextos de crecimiento, mejora o desarrollo. Por un lado el vocablo "sostenible" tiene su origen en la palabra "sostenido", cuyo significado es que algo puede mantenerse por un tiempo determinado; por otro lado, "sostenible" significa que algo se puede mantener por tiempo indefinido, sin que colapse o se deteriore. Por su parte, "sustentable" se origina del verbo "sustentar", cuyo significado se enfoca hacia un proceso independiente, que no necesita de recursos externos para mantenerse (Rivera-Hernández, 2017)

7 Ese intercambio fue financiado por el programa CAPES-NUFFIC, entre la Universidad Federal de Santa Catarina, Florianópolis (SC), Brasil, y la Universidad VU Amsterdam, Amsterdam, Holanda.
} 
cual participe. Basándome en relatos etnográficos que traigo, como datos centrales para la comprensión de la relación que establezco entre remo, ciudad y agua limpia. Partiendo de dos preguntas fundamentales que nortean mis pasos y los ejes comparativos en mis reflexiones: la primera ¿cuáles son estas experiencias innovadoras para el tratamiento de residuos sólidos que han incorporado al remo deportivo? y la segunda, ¿cómo el compromiso de los atletas del remo ayuda a transformar la realidad y el paisaje urbano de estas dos metrópolis?

\section{El surgimiento del remo deportivo en Amsterdam y Florianópolis}

Sabemos por la historiografía, que el origen del remo como actividad deportiva se remonta a principios del siglo XIX. Cuando, a orillas del Támesis, en Londres, empezaron a surgir las primeras disputas recreativas entre embarcaciones asociadas directamente a una competición deportiva. A partir de ahí, varios clubes de remo surgen a orillas de los ríos europeos. La primera Universidad Inglesa en incluir el remo como actividad recreativa fue la Universidad de Eton, en 1806. Cinco años después, en 1811, el remo sería titular en un importante periódico, asociándolo a "nuevos deporte" ${ }^{8}$ (Caje, 2020:17).

En 1814, tras el fin de las guerras napoleónicas, el remo por fin se instala en toda Inglaterra como un deporte nacional, dando lugar a una disciplina militar para jóvenes que regresaban de la guerra. Esta práctica se importó rápidamente a las principales ciudades de los Estados Unidos - Nueva York, Boston y Chicago - permaneciendo efervescente solo dentro del mundo anglosajón durante casi veinte años. Recién en 1830 aparecieron los primeros registros de competiciones en Francia, como una adaptación a la práctica del canotier, que tenía como objetivo la recreación y una ruptura con el tiempo del trabajo.

Francia asumiría rápidamente un papel hegemónico dentro del circuito internacional de remo. En 1892, se fundó en París la Fédération Internationale des

Comparando prácticas sociotécnicas de gestión de resíduos sólidos en tres diferentes países: Brasil, Holanda e Indonesia.

${ }^{8}$ En 1813, la Universidad de Cambridge y Westminster School ya habían formado sus primeros equipos, organizando las primeras carreras entre jóvenes estudiantes de la élite inglesa. El entusiasmo por el remo deportivo fue creciendo y los desafíos entre escuelas y universidades dieron inicio a los primeros encuentros para establecer permanentemente el remo como deporte . 
Sociétés D'Aviron, actualmente conocida como FISA. Estructurada a partir de las Sociedades Francesas de Gimnasia, las reglas internacionales para el remo deportivo. A partir de ahí, el aviron (remero en francés), o el rower (remero en inglés), pasarían a ser calculados por sus masas corporales, aliadas a la embarcación, se produciría ropa para un mejor movimiento de la musculatura en el acto de la carrera y el remo vería su evolución como deporte se basa en la clasificación de las carreras según el número de remeros.

Para Norbert Elias (1992), uno de los principales investigadores sociales en pensar el lugar del deporte dentro de ese contexto de la modernidad, llamó este proceso de "proceso civilizador". Y lo describió como una "educación del cuerpo, en la contención de impulsos, en el refinamiento de los gustos, en el cambio de percepción de los sentidos y en una nueva organización del tiempo y del espacio" (Elias,1992:75) llamando la atención a todas las posibilidades de someter al cuerpo en un subjetividad que denomino de "ethos deportivo".

Florianópolis y Amsterdam, aunque de manera diferente, han tenido una larga y exitosa trayectoria en ese proceso descrito por Elias (1992). El remo llegó a tener una masiva participación de las elites y una gran cobertura mediática en el pasaje secular del XIX para el XX. Amsterdam se mantiene activa dentro del escenario deportivo global bastante agitado, con nueve clubes distribuidos por la ciudad, la mayoría de ellos sobre el río Amstel, y es considerada como una de las potencias del remo mundial en la actualidad. Holanda fue uno de los países que dio origen al remo en Europa, junto a ciudades como París y Londres (Caje, 2020:19). En los Juegos Olímpicos de Verano de 1928, celebrados en Amsterdam, el rowing o remo, ya aparecía como un deporte olímpico, y en los últimos Juegos Olímpicos de Río de Janeiro (2016) llegaron a ganar varias medallas de oro, con destaques en las categorías lideradas por mujeres ${ }^{9}$.

\footnotetext{
9 En el doble de peso ligero de mujeres. división de sculls, han sido las primeras clasificadas. Las mujeres tienen mucha participación en el remo holandez, a diferencia de Brasil, donde las mujeres ocupan un lugar todavía muy marginal, salvo algunas excepciones como el caso de Fabiana Beltrame.
} 


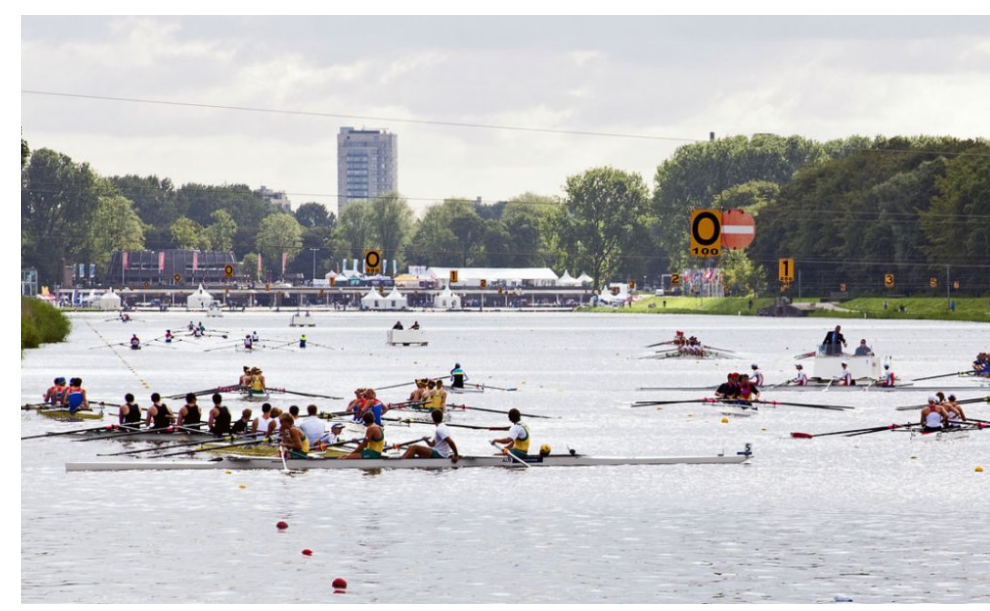

Imagen 1- Rowing in the Netherlands (09 Febrero 2018).

Fuente: www.iamexpat.nl visitado el 12 de mayo de 2020.

Si bien es un deporte muy popular entre los holandeses, la mayoría de los clubes se mantienen específicos para estudiantes. Algunos son abiertos a la comunidad en general y todos exigen un certificado que ateste que la persona sabe nadar, antes de matricularse. En general, son lugares para socializar, ejercitarse y a menudo organizan una cena semanal, o un juego de bingo, a lo que los socios pueden inscribirse, como una forma de reunir a los miembros. Este es un un estilo bien Holandez de vivir la ciudad y de mantener el espíritu comunitario. Como vimos en la Imagen 1, con toda esa agua alrededor, es muy común ver por los canales, barcos, velas, kayak, siempre alguien remando. Y con toda la popularidad y sin embargo, por más que no aparezca en los noticieros diariamente, es bastante conocido y sus atletas son como sub celebridades nacionales, especialmente entre estudiantes universitarios.

Ya en Brasil, el remo solo llegaría a fines del siglo XIX, coincidiendo con eventos políticos y económicos importantes, como la Proclamación de la República, la Guerra del Paraguay y la abolición de la esclavitud, instalándose y afirmandose como deporte nacional dentro de un ciclo modernizador que ayudaría a la emergencia de una nueva republica. Río de Janeiro y Porto Alegre tendrían los primeros Clubes Náuticos organizados por inmigrantes franceses, alemanes y portugueses. El primer Club de remo en registrarse fue la Unión de Canotiers en 1892, en Río de Janeiro y el Ruder Club Porto Alegre de 1888, en Porto Alegre (Caje, 2020). Los nombres de estos primeros clubes muestran la doble influencia del francés y del inglés en el deporte.

En Florianópolis, el remo llegaría solo en 1903, con la fundación del Club de Regatas 29 de Abril. Vinculado a la federación de remo de Río de Janeiro, y que cerraría sus puertas tres años más tarde, sin algún motivo claro. Y sólo entre 1915 y 
1918, con la fundación de los Clubes Náuticos Riachuelo, Martinelli y el Clube de Regatas Aldo Luz, que el remo deportivo adquirirá su característica de práctica deportiva moderna, inserida en un contexto de transformaciones urbanas y cívicas que se llevaron a cabo y que tenían como objetivo limpiar la ciudad y darle a sus habitantes un aspecto de capital.

De esta forma, se fomentaría la práctica del remo entre intelectuales, políticos, comerciantes y la élite social local, que se involucraron rápidamente con la práctica náutica donde eran vistos como héroes al mostrar su fuerza, belleza y disciplina (Sartori, 2013). El remo como actividad deportiva llegaría a una Florianópolis con características isleñas pero con grandes deseos de ser una metrópolis. Donde se encontraría con el remo como transporte marítimo atendiendo la necesidad de transporte urbano y vinculado al movimiento de personas, mercancías y todo tipo de bienes de consumo, como la pesca, extracción, vertido y como medio de comunicación (Ferreira, 1998:36).

Desde su llegada, el remo deportivo se vinculó a la identidad urbana de la Florianopolis moderna, representando los impulsos evocadores de la vida social de una modernidad que no existe más. A partir de los años 1940, la ascensión del fútbol como deporte nacional, que de hecho, fue una de las dificultades en investigar este deporte dentro del campo de las ciencias sociales es la dificultad para encontrar bibliografías. Donde buscamos remo, siempre encontramos fútbol. La situación del remo en Florianópolis de hoy, dentro del campo de producción teórica, se limita al esfuerzo casi individual de historiadores y amantes del deporte que sustentan la memoria de los "tiempos de glorias" (Caje, 2020).

Las competiciones de barcos, que alcanzaron su punto máximo de popularidad entre las décadas de 1920 y 1940, una época conocida como los "tiempos de gloria" del remo, son compartidas hoy entre los atletas remeros de varias generaciones. Que se reúnen mensualmente durante las competencias que suceden generalmente los sábados, en las rayas de la costa norte, o de la costa sur de la beira mar de Florianópolis. Historias y memorias de fragmentos que se mezclan y confunden, para construir una verdad sobre las hazañas de los barcos de un tiempo ya ido.

En la imagen 2 podemos ver como un barco rema para mantenerse visible en el paisaje, devorado por las grandes infraestructuras urbanas que sumergieron a la bahía de Florianópolis, desde mediados de los años de 1960, a casi un lugar olvidado. La 
decadencia del remo se entrelaza al desarrollo urbanístico y social de la capital en la actualidad.

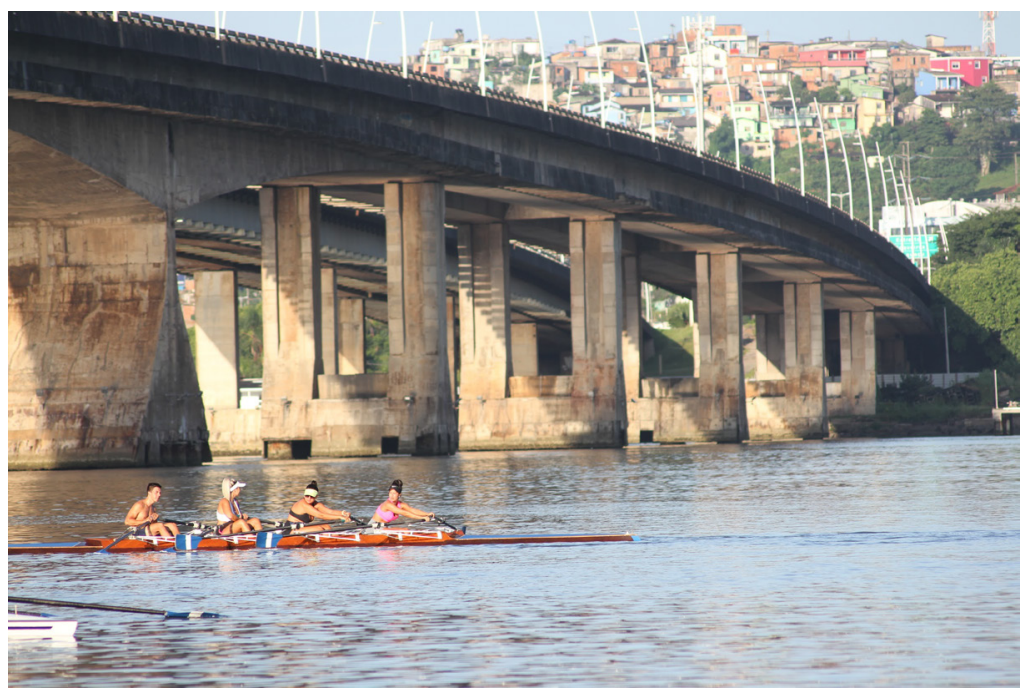

Imagen 2 - Remeras y remeros bajo el puente Colombo Salles. Fuente: acervo de Denise Becker, 2018.

\section{El agua y las transformaciones urbanas}

Así como los cuerpos, los espacios urbanos también pasarían por modificaciones emprendidas por las demandas de la modernidad. En Europa, tanto en Francia como en Inglaterra, las competiciones de remo atraerán a un número considerable de espectadores en las orillas del Sena y el Támesis. Los gobierno europeos, los clubes náuticos y la prensa luego se darían cuenta de la necesidad de organizar y disciplinar a los observadores de las regatas en espacios más apropiados. Y ya sea en París o en Londres, la práctica de ejercicios físicos y deportivos, se estructuraron en un contexto de revolución industrial, de urbanización y de nuevos nacionalismos. El deporte y la recreación pasaría a ser considerada una prioridad para la política cultural de esos países.

Florianópolis y Amsterdam pasarían por procesos de transformación urbanas bastante parecidas, en lo que se refiere a la presencia y al control del agua en los espacios urbanos (Sartori, 2013; Cabral, 1994; Shorto, 2013). Amsterdam ya tenía una tradición que venía de un par de siglos de historia detrás, con la construcción de diques y canales de dragado que fueron actividades comunales y masivas en las que todos los ciudadanos que tenían algún interés en conseguir tierras tenían que participar. Como cuenta Shorto:

La pesca en la costa requería poco más que un padre y un hijo y algunas manos, pero mudarse a aguas profundas significaba un compromiso de capital y una compleja infraestructura de apoyo. Las 
naves eran más grandes y tenían equipos de trabajadores especializados: marineros, canalones (un equipo experto de canalones podía procesar 2,000 arenques por hora), empacadores, oficiales. Como una flota de arenque tenía tal ". (Shorto 2013:90) Traducción del autor

Hoy en día, una parte importante del territorio Holandes está literalmente por debajo del nivel del mar. Después de muchos años empujando lagos y océanos, construyendo canales, inundando áreas de propósito, estableciendo una relación omnipresente de sus ciudades con el agua. La recuperación de tierras alrededor de la antigua isla de Urk, por ejemplo, bastante emblemática, como vemos en la imagen 3, empezó a principios del siglo XX, se extendió hasta el año de 1940 - sólo fue interrumpida a causa de la Segunda Guerra Mundial. El uso de las tierras recuperadas se concentró principalmente en la agricultura y las áreas menos fértiles fueron designadas para ser plantadas como tierras forestales, pasando a ser propiedad del estado. Las tierras recuperadas se distribuyeron prioritariamente para los primeros pioneros que las habían ocupado. Más tarde, los agricultores del resto del país se hicieron elegibles para el resto del territorio.
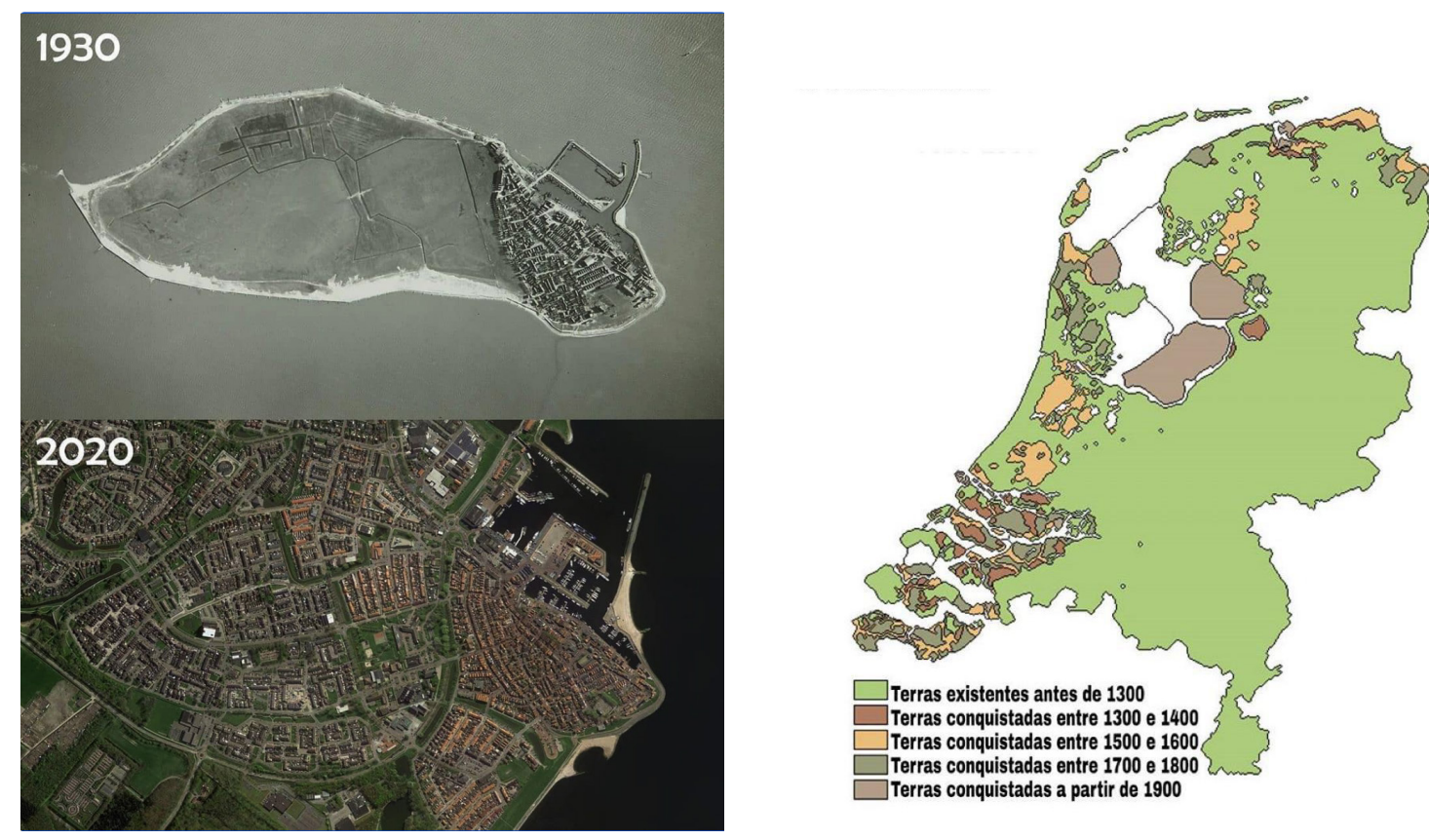

Imagen 3 - Recuperación de tierras alrededor

Imagen 4 - La expansión de Holanda sobre el mar. de la antigua isla de Urk. Fuente: @geografiageral. Fuente: @geografiageral. Visitado el 11 de junio de Visitado el 11 de junio de 2020. 2020 
Según datos de la revista @geografiageral, como vemos en la imagen 4, alrededor del $17 \%$ de la superficie actual del país, se ha recuperado del mar o los lagos. El 26\% de su superficie se encuentra por debajo del nivel del mar. El 21\% de su población vive en áreas bajo el nivel del mar y solo el 50\% de su superficie se encuentra a más de 1 metro sobre el nivel del mar. El punto más bajo: Zuidplaspolder $-7 \mathrm{~m}$ bajo el nivel del mar, y el punto más alto: Vaalserberg, 322,7 m sobre el nivel del mar. Flevoland es la provincia holandesa más reciente y solo se creó en 1986 en una tierra que fue conquistada por el agua, en las décadas de 1950 y 1960.

Amsterdam, sin embargo, surgió en el siglo XIII como una comunidad de pescadores a orillas del río Amstel. En 1270, el río se canalizó y gran parte se llenó para evitar inundaciones, lo que influyó en el nombre de la ciudad como Amsterdam, que significa "la presa de Amstel" en holandés. A principios del siglo XVI, Ámsterdam se fortificó, ganando canales que daban forma a su tejido urbano en un patrón geométrico a cuadros, como vemos en la imagen 5. La ciudad, dentro de la provincia de Holanda, se ha convertido en uno de los puertos más importantes del Mar Báltico y de todo el norte de Europa. Hoy en día, el centro de Ámsterdam está dividido en unas 90 "islas" y el municipio contiene 1.300 puentes y viaductos, y $1 / 5$ de sus habitantes utilizan bicicletas como mediode transporte (@geopizza, 2020).

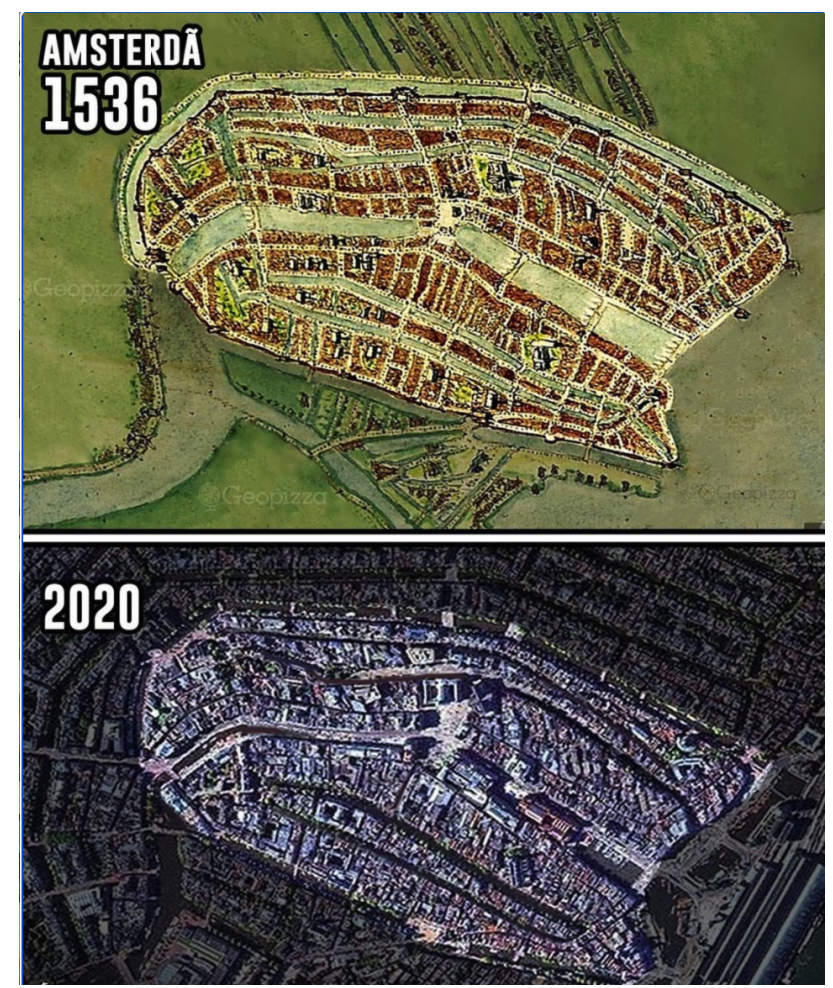

Imagen 5 - Transformaciones de Amsterdam.

Fuente: @geopizza. Visitado el 11 de junio de 2020. 
En Florianópolis, ese proyecto de crecimiento urbano se instaló con fuerza a finales de la década de 1960, con el objetivo de ampliar la zonificación urbana y promover la circulación de bienes y personas, con la promesa de que aportarían beneficios a través de apropiación y uso de los espacios construidos (Caje, 2020). Así, aparece el terraplén de la bahía sur. En ese momento, la construcción de vertederos se consideró fundamental para el desarrollo y el status quo del municipio de Florianópolis, que, según Cunha (2005:5), creció intensamente después de crear un área de desarrollo triangular con vértices que descansan sobre el puente e al oeste, sur y norte, enterrando la región de Rita María a la región de Prainha.

En la imagen 6, podemos ver como los clubes de remo fueron retirados del centro de ciudad y colocados en la nueva región del terraplén de la bahía sur, llamado Parque Náutico Walter Lange, bajo los puentes Colombo Salles y Pedro Ivo.

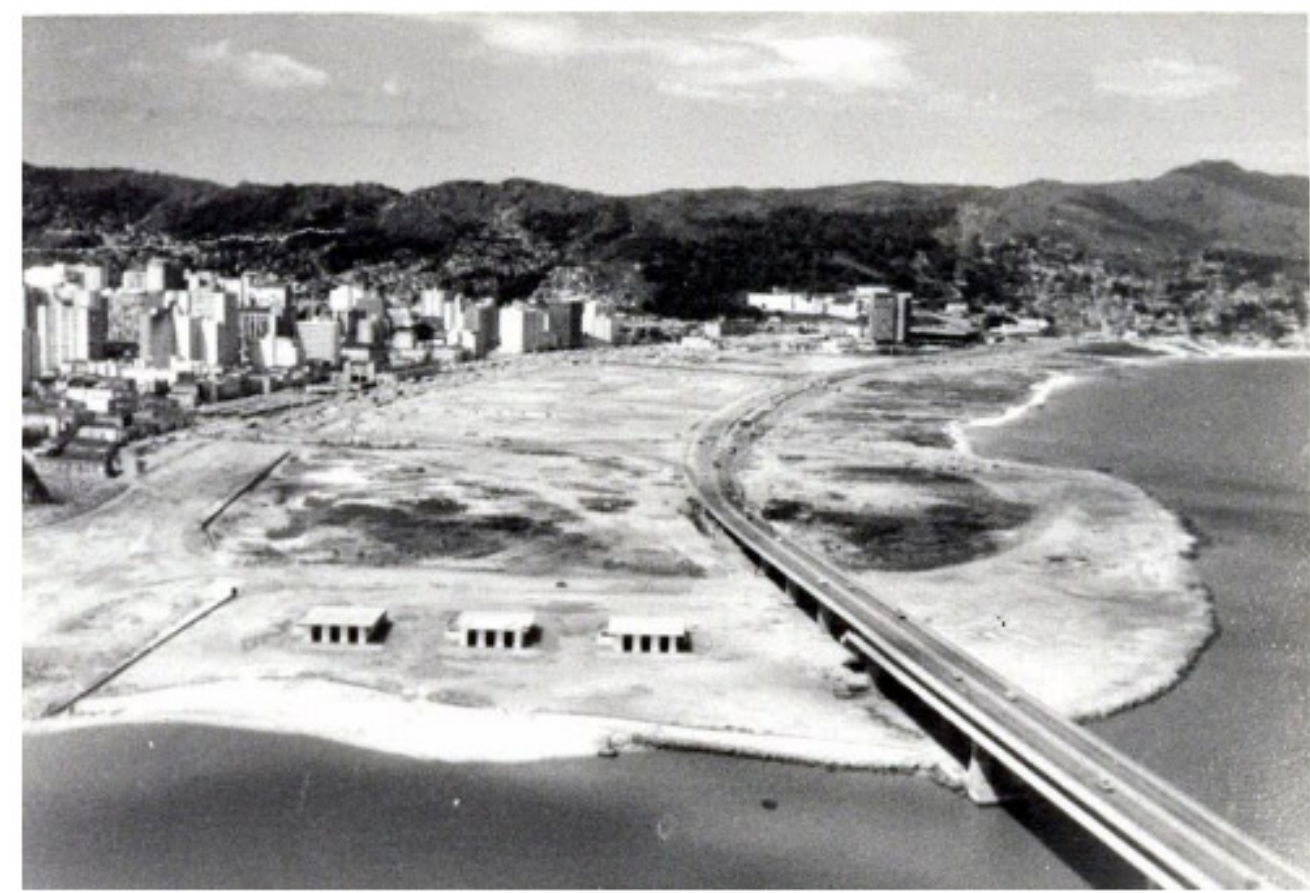

Imagen 6 - Terraplanado de la baía norte. By Jean A. Lima | Published 13 de April de $2013 \mid$ Fuente: Club Naútico Francisco Martinelli.

El terraplenado acabó configurando la formación urbana de Florianópolis y, a partir del año de 1972, empezaron a surgir nuevas áreas comerciales, portuarias, industriales y residenciales en diferentes lugares dentro o alrededor de ella. Modeló la expansión de la costa y, con eso, el desarrollo de actividades comerciales vinculadas a la 
actividad portuaria. Avanzó la ciudad, pero el mar se contrajo, desde la perspectiva de los remeros. Fueron retirados del centro y reubicados, "tirados", en palabras de ellos.

Con el terraplén de la bahía sur, los tiempos dorados del remo de Florianópolis fueron enterrados en la memoria de las generaciones pasadas. Fotografías de la colección Clube Náutico Riachuelo (imagen 7), que ilustran las multitudes llenas de gente para ver las regatas, la afición organizado para cada club agrupado en las calles cercanas al Mercado Público, las calles de centro invadido por la fiesta de los ganadores, todo eso quedó en la memoria de quienes hoy evocan el recuerdo. Hoy, es posible observar cómo las grandes infraestructuras que rodean al Parque, se tragaron y aislaron los clubes, dificultando su acceso, quedando casi ocultos del paisaje urbano, destinando los al umbral del olvido.

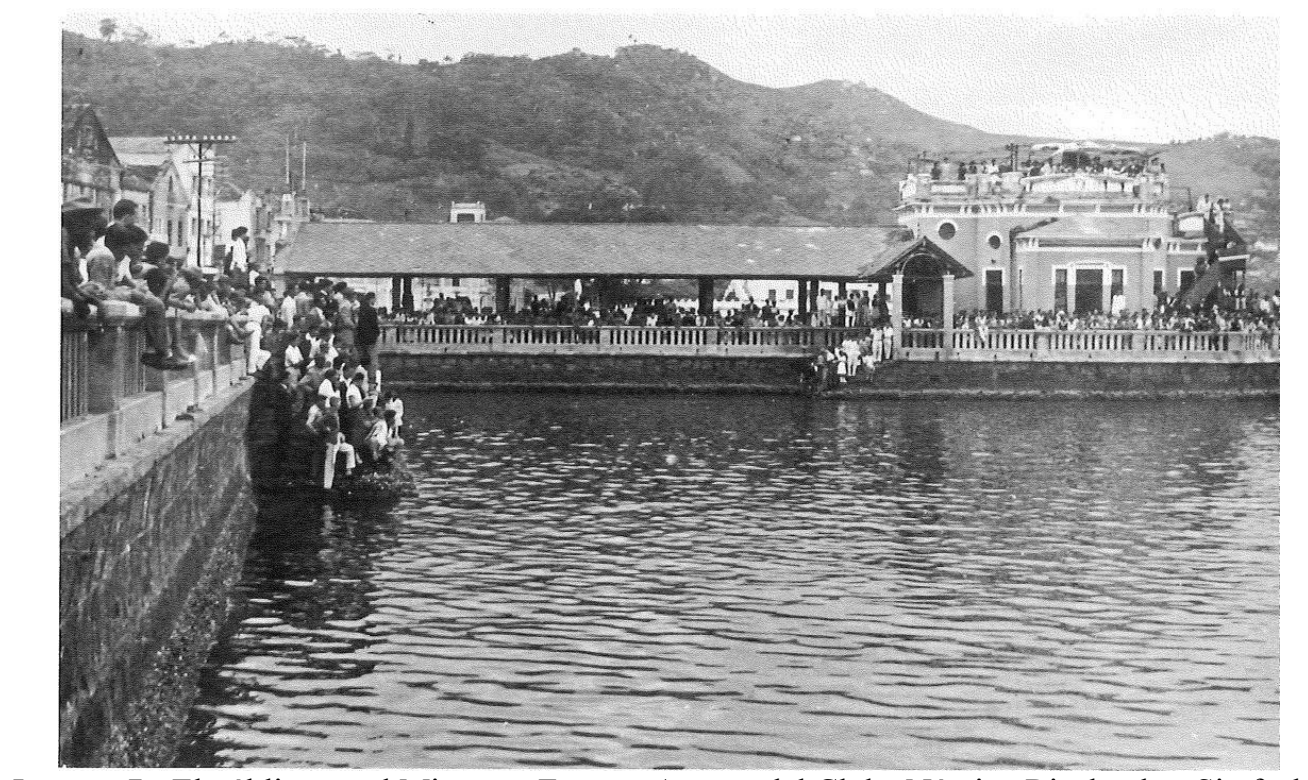

Imagen 7 - El público en el Miramar. Fuente: Acervo del Clube Náutico Riachuelo - Sin fecha

\section{Los residuos sólidos sumado a lo útil en Amsterdam}

Los 120 canales - unos $100 \mathrm{~km}$ aproximadamente - que impregnan toda la ciudad no son solo una atracción turística. Siempre han tenido importancia comercial. Pero es cierto que navegando por ellos, viendo el reflejo en las aguas, de los edificios del siglo XVII, no todo alrededor parece tan turístico. Los canales - construidos hace 400 años, con una profundidad media de dos a tres metros - son una vía de transporte importante y muy utilizada cotidianamente. Como vimos antes, desde pequeñas embarcaciones hasta grandes embarcaciones, con capacidad para 200 pasajeros, sin 
“El remo, nuestro deporte, requiere agua limpia”. Experiencias innovadoras de saneamento...

mencionar los cargueros aparecen entre un canal $y$ otro.

Algunos de los 800.000 habitantes de Amsterdam viven en barcos flotantes, que siempre están amarrados en el mismo lugar y conectados a la red de agua, luz y gas. Hoy en día existen más de 2.500 casas flotantes, la mayoría de las cuales también están conectadas a la red de alcantarillado municipal. Por ley, también deben calentarse para protegerse de los fríos días de invierno. Está prohibido tirar cualquier cosa en el canal, sin embargo, como en otros lugares, lo prohibido no siempre es regla. En cuanto a la limpieza del agua de los canales, hay mucha discusión. Las casas de botes que aún no tienen tuberías de alcantarillado arrojan piedras allí.

La empresa pública Waternet, que visité en 2018 - una empresa de capital privado, como casi todo lo publicó en Holanda - es la responsable de la calidad del agua en los canales. Mantiene diariamente algunas embarcaciones navegando para recoger lo que se tira al agua, unos 3.500 kilos de basura, incluidas bicicletas oxidadas, como vemos en la imagen 8. Sabemos que las bicicletas son el medio de transporte más utilizado por los holandeses - alrededor de 350 mil que circulan por la ciudad, una media de dos bicicletas por cada habitante. Y eso obviamente es un problema de contaminación del agua, gigantesco.

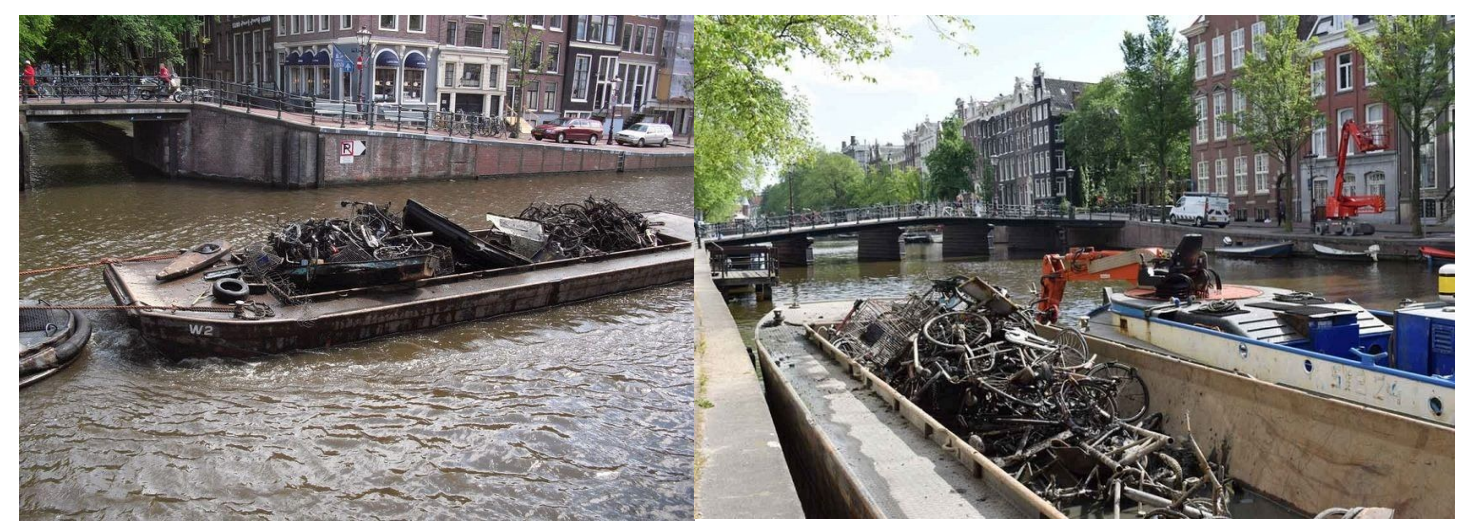

Imagen 8 - Embarcación de la empresa Waternet recogiendo bicicletas. Fuente: site:omyamsterdamtours - 2018

El funcionario municipal, Tomás, en una entrevista que me concedió en diciembre de 2018, declaró, "el agua en Amsterdam es más limpia de lo que parece”, refiriéndose a su color parduzco. Me explicó que los canales se purifican abriendo las 
compuertas del río Amstel dos veces por semana: "los pececillos están regresando y también los pájaros que se alimentan de ellos; en el pasado, el agua estaba mucho más sucia y olía mal", declaró. Tomás comenta que ya se han encontrado refrigeradores, cochecitos, muebles e incluso animales muertos. En aquel año, el municipio tenía previsto instalar la red de alcantarillado a lo largo de los canales, conectando todas las embarcaciones, pero también parecía ser una frustración para Tomás, que reclama de la mala gestión de la municipalidad. Porque según él, el origen de la gran cantidad de residuos estaría en la política turística. Dos años antes de mi llegada a Ámsterdam, una iniciativa que juntaba turismo y limpieza de los canales había ganado mucha visibilidad y adherencia del público. Con la promesa de poder sumarse a "una gran casa" y ayudar a reducir el volumen de plásticos que contaminan las aguas del planeta. La empresa social Plastic Whale, la primera empresa de pesca de plásticos profesional, como se presenta en su página $w_{e} b^{10}$, surgió como una alternativa para que citadinos y turistas pudieran pescar plásticos a través de los canales de la ciudad. Con la misión de "hacer que las aguas del mundo estén libres de plástico y crear valor a partir de estos desechos". Plastic Whale comenzó con el desafío único de construir un bote con desechos plásticos. Hoy en día, cuenta con una flota de embarcaciones fabricadas con materiales extraídos de los canales. Como vemos en la imagen 9.

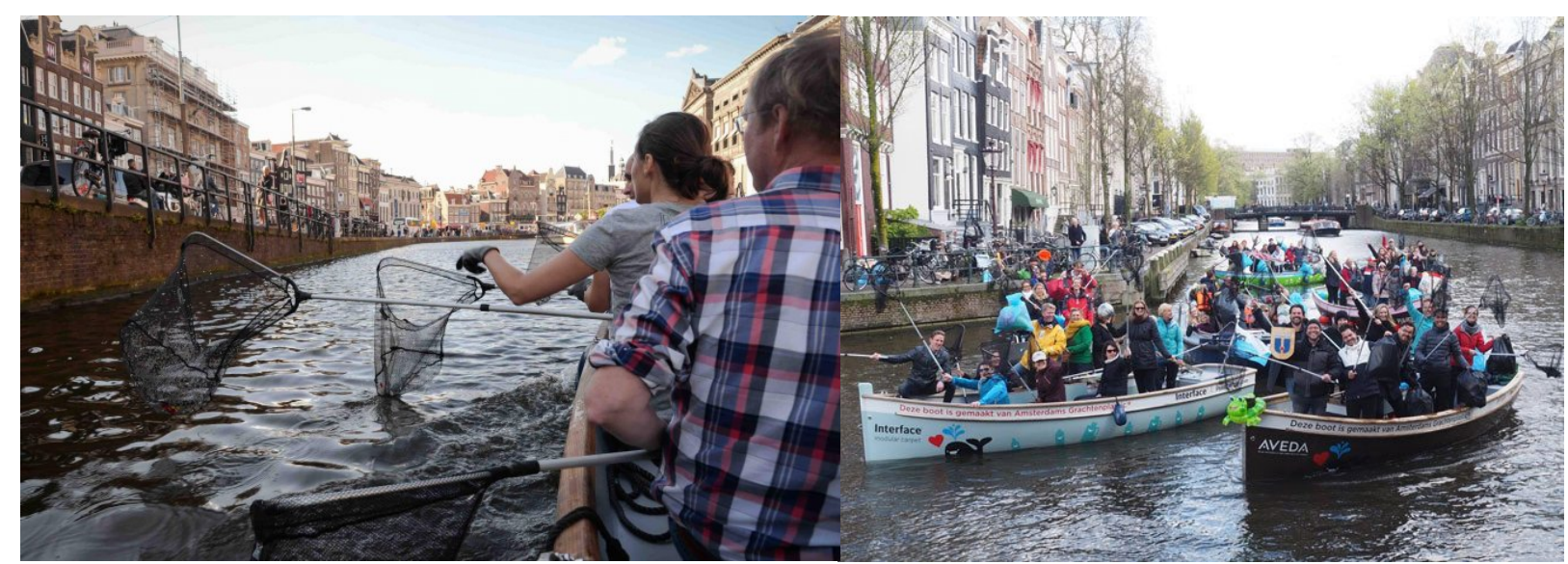

Imagen 9 -

Embarcaciones de la empresa Plastic Whale.

Fuente: site:plasticwhale.com - 2018

${ }^{10}$ https://plasticwhale.com/ Acessado em agosto de 2020. 
Ese ejemplo positivo, altamente promocionado y con un público que buscaba hacer algo para poner fin a los residuos sólidos en las aguas de los canales, enseguida se extendió y se adaptó al cotidiano de los clubes de remo. Claro que con mucho menos infraestructura empresarial, y mucho más enfocado a acciones determinadas, restrita a asociados y atletas, la posibilidad de juntar actividad deportiva con participación y compromiso con el medio ambiente.

\section{"Florianópolis no tiene saneamiento"}

Fue la expresión que usó Loreno, un remero interlocutor en campo, cuando frecuentaba los galpones de Clube Náutico Riachuelo, en Florianópolis, allá por 2017. Recuerdo que un año antes, durante las olimpiadas de Río 2016, los atletas del remo se habían convertido en agentes denunciadores de la contaminación extrema del agua de la Lagoa Rodrigo de Freitas. Rio, como una ciudad emblemática de la modernidad Brasileña, donde la mayoría de las aguas residuales continúa con graves problemas de tratamientos del agua y una gran cantidad de desechos sólidos fluyen a través de acequias abiertas hacia arroyos y ríos que alimentan las sedes de las competencias acuáticas de los Juegos Olímpicos. Así como Loreno, que se refiere a la bahía norte de Florianópolis en aquel entonces, los atletas que compitieron en los Juegos Olímpicos de 2016 tuvieron que nadar y navegar en aguas tan contaminadas por heces humanas que corren el riesgo de contraer una enfermedad y no poder completar las pruebas.

La trayectoria histórica del primer sistema de alcantarillado en Florianópolis es bastante emblemática. Comenzó a funcionar en febrero de 1913, en el Gobierno de Vidal Ramos, abarcando únicamente la zona central de la Isla, coincidiendo con la llegada del remo deportivo y las reformas urbanas modernizadoras. A principios de 1914, el trabajo fue paralizado por las dificultades ocasionadas por la guerra contra el Paraguay y la falta de fondos, concluyendo las obras solamente en Septiembre de 1916, bajo Felipe Schmidt. El sistema constaba de un conjunto de redes colectores, desde los cuales se enviaban las aguas residuales a la planta de tratamiento, por gravedad o mediante bombeo realizado por tres estaciones elevadoras denominadas "Castelinhos" y 
ubicadas: uno en Praça XV de Novembro, otro en Praça São Sebastião y el tercero en Praça Celso Ramos (Ramo, 1986).

Todos los "Castelinhos" se conservan actualmente y están en proceso de restauración. La estación depuradora estaba ubicada en las cercanías del Puente Hercílio Luz, cerca del Fuerte Santana, y utilizó el proceso de tratamiento mediante fangos activados por aire difuso. En 1923, debido al aumento en la contribución de las aguas residuales producto del crecimiento de la población, el sistema comenzó a presentar problemas operativos, trabajando gradualmente con sobrecarga.

Hacia 1951, se desactivó la estación depuradora y todas las aguas residuales recogido, del sistema implantado, comienza a ser arrojado directamente al mar junto con el efluentes de las conexiones individuales que la población ha venido ejecutando, a lo largo de los años, en el drenaje pluvial. Sólo a partir de 1978, las obras resultantes de una nueva Propuesta de alcantarillado municipal (Ramos, 1986: 45).

Actualmente, el índice de población urbana atendida con servicios de recolección y tratamiento de agua en el municipio ronda el $40 \%$, lo que también muestra la necesidad de grandes inversiones, especialmente en el sur de la Isla, donde además del turismo, actividades en el área de maricultura.

Desde la década de 1970 en adelante, con el aumento considerable de la población urbana en la isla, la preocupación por una mayor atención al agua, en relación al destino final de la basura, se consolida un movimiento social más comprometido con el medio ambiente. Es en ese contexto histórico, de mucha precariedad en relación al cuidado del agua urbana, surge solamente en 2020 el Movimiento Floripa Sustentable. Un emprendimiento de iniciativa privada, reuniendo empresarios, políticos y amigos de los clubes de remo, para tratar de revitalizar la región de los galpones. Enfocando especialmente a lo que se refiere al saneamiento de las aguas donde se practica el deporte, agua limpia y práctica deportiva. Claro que como su nombre ya lo anuncia, detrás de la idea sustentable están por detrás toda la lógica empresarial de vida saludable, naturaleza, globalización limpia y consumo consciente. Como elementos constituyentes hoy del mercado de la clase media Florianopolitana.

Es la primera vez que los clubes de remo de la ciudad empiezan una campaña más sincronizada, que busca no solo reformas en el ámbito de la estructura del parque náutico, que cedía los clubes, más como explica Loreno: "Esa región está abandonada y 
degradada, a pesar de que los clubes de remo cuidan el espacio. Es importante que la zona tenga más flujo de personas, generando más seguridad a la región, además de generar un uso dinámico del deporte y el esparcimiento para toda la población". "Hay que recuperar el alma de la ciudad", dice. Apuntando el dedo para algunos lugares que aparecen en la imagen 10, abajo.

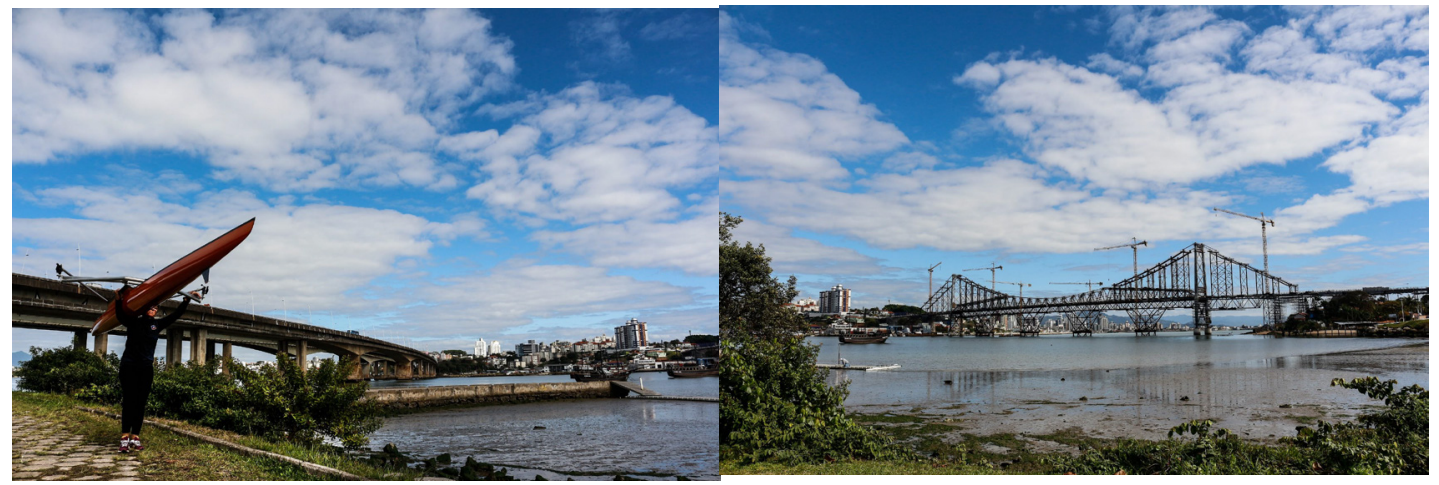

Imagen 10 - Parque Náutico Walter Lages. Fuente: archivo personal - 2018

\section{Consideraciones finales}

La Organización Mundial de la Salud (OMS) define el agua contaminada como aquella cuya "composición haya sido modificada de modo que no reúna las condiciones para el uso que se le hubiera destinado en su estado natural". El agua es uno de los elementos naturales que se encuentra en mayor cantidad tanto en Florianópolis como en Amsterdam. También es gran responsable de la posibilidad de desarrollo de estas dos ciudades, como vimos a lo largo de este trabajo, la relación histórica que ambas conllevan con la presencia del agua urbana, sea en forma de canales, sea en forma de bahías. Tanto el agua, como el remo son elementos que las constituyen. No en vano, Holanda desarrolló un polo de estudios en esta área. La preocupación por el agua en el país es histórica también. Un tercio de su territorio se encuentra por debajo del nivel del mar. Desde 1800, Holanda ha comenzado a crear consejos públicos, que en el modelo actual son elegidos por la población cada cuatro años y están autorizados a recaudar impuestos y realizar las obras necesarias para abastecer, almacenar y tratar el agua, así como para mantener la seguridad contra 
inundaciones y tormentas. En total, el 98\% de los hogares en los Países Bajos están conectados a la red pública de saneamiento (en Brasil, son el 30\%). Estos consejos, que eran 1700 en el siglo XIX, ahora son 24. En 2014, la Organización para la Cooperación y el Desarrollo Económicos reconoció la gestión del sistema de agua del país como un modelo para el mundo (Matos de Souza, Pereira Santos, 2016).

Como la comunidad europea es en general pionera en la implementación de estas acciones que se utilizan como base en Brasil. El análisis comparativo simplificado permitió la percepción de que, en términos geográficos, las dos ciudades tienen características muy similares: por un lado, Amsterdam, de extensión territorial mucho menor, se encuentra por debajo del nivel del mar; por otro lado, Florianópolis, con gran extensión territorial y abundancia de recursos naturales, pero con gran heterogeneidad socio-económico-geográfica, bajo índice educativo, alta burocratización, deficiente administración pública, etc.

Además, a lo largo de la historia hemos notado que las limitaciones de recursos estimulan la búsqueda de soluciones alternativas e incluso más eficientes. Sin embargo, el escenario actual de contaminación de las fuentes de agua superficiales nos obliga a tomar una actitud más comprometida. En vista de lo anterior, es posible percibir grandes diferencias en términos de posicionamiento en relación a los servicios de saneamiento entre Amsterdam y Florianópolis. Por un lado, Florianópolis empieza a preocupar se por elevar una gestión eficiente con infraestructura adecuada, educación e involucramiento de la población e inspección. Por otro lado, Amsterdam, que ya cuenta con altísimos índices de servicio a los servicios de saneamiento, busca nuevas formas creativas, como el remo, sostenibles e invierte recursos para garantizar servicios de calidad. Además, existe una gran preocupación por parte del gobierno y las instituciones holandesas en promover la participación de la población y la construcción de una gestión participativa eficaz. 


\section{REFERENCIAS}

CABRAL, O. R. História de Santa Catarina. Florianópolis: Lunardelli, 1994.

CABRAL, Oswaldo Rodrigues. Nossa Senhora do Desterro. Florianópolis: Ed. Lunardelli, 1979.

CAJE RODRIGUEZ, Cristhian. Os vencedores cheios de glória: articulações entre masculinidades e memória na imagem do remo em Florianópolis. Tese (Doutorado em Antropologia Social). Florianópolis: Universidade Federal de Santa Catarina, 2020.

CUNHA, G.S.: Considerações sobre o aterro de Florianópolis, 2005. 10 f. Trabalho de conclusão de Curso (graduação) - Universidade Federal de Santa Catarina.

GRUPO DO LIXO. Considerando Mais o Lixo. Florianópolis: Ed. Insular, 1999.

LATOUR, Bruno. (2015), Face à Gaïa. Paris, La Découverte.

RAMOS, Átila. Memórias do Saneamento Desterrense. Florianópolis: Ed. CASAN, 1986.

RAMOS, Átila. Saneamento Básico Catarinense. Florianópolis: Ed. IOESC, 1991.

RAMOS, Átila. O Saneamento em dois Tempos. Desterro e Florianópolis. Florianópolis: Ed. CASAN, 1983.

RIVERA-HERNÁNDEZ, Jaime Ernesto. ¿Desarrollo sostenible o sustentable? La controversia de un concepto. Revista Posgrado y Sociedad, Sistema de Estudios de 
Posgrado, Universidad Estatal a Distancia. ISSN: 2215-2172. Volumen 15, Número 1, 2017, 57-67.

MATOS DE SOUZA, Michelle. PEREIRA SANTOS, Ana Silvia. Drinking water, wastewater and sanitation in Brazil and in The Netherlands within the Dutch Visitation Program - DVP: Dutch Visitors Programme. Eng. Sanit. Ambient. vol.21 no.2 Rio de Janeiro Apr./June 2016.

MEYER, Mário Francisco; SARTORATO, Jair e SILVA, Maria Aparecida. Os Serviços de Esgotos no Município de Florianópolis-SC: Histórico, situação atual e perspectivas. Florianópolis: Ed. CASAN, 1998.

ORFINO, Flávia V. G.; OLIVEIRA, Maria Tereza. Reciclagem de Lixo: A Participação da Empresa Municipal de Limpeza Urbana de Florianópolis. Florianópolis, 1999. Mimeo.

SARTORI, Carina. Na alvorada de um sport: o remo na ilha de Santa Catarina. Dissertação (Mestrado em História). Florianópolis: Universidade Federal de Santa Catarina, Centro de Filosofia e Ciências Humanas, 2013.

SHORTO, Russell. Amsterdam : a history of the world's most liberal city. — First Edition.Amsterdam(Netherlands) History.Liberalism. Netherlands-Amsterdam-History. Apple Books. 2013, Vol, 3.1.

SILVA, Dalton. Os Esgotos Sanitários de Florianópolis. Florianópolis, 1989. Dissertação de Mestrado. UFSC.

STENGERS, Isabelle. No tempo das catástrofes: resistir à barbárie que se aproxima. Tradução Eloisa Araújo Ribeiro. São Paulo: Cosac Naify, 2015. (Coleção Exit).

STENGERS, Isabelle. Gaia, the urgency to think (and feel). In: COLÓQUIO INTERNACIONAL OS MIL NOMES DE GAIA DO ANTROPOCENO À IDADE DA 
TERRA, 2014, Rio de Janeiro. Anais eletrônicos... Rio de Janeiro: Departamento de Filosofia/PPGAS/Museu Nacional/UFRJ, 2014.

LOPES, Wilson R. C.; OLIVEIRA, Maria Tereza de. A questão dos resíduos sólidos urbanos e o sistema jurídico brasileiro - Caso de Florianópolis. Florianópolis, 1997. Mimeo.

Recebido: 06/09/2020

Aprovado: $08 / 12 / 2020$ 